\title{
Valor nutricional de cogumelos comestíveis
}

\author{
Nutritional value of edible mushrooms
}

\author{
Regina Prado Zanes FURLANI ${ }^{*}$, Helena Teixeira GODOY ${ }^{2}$
}

\begin{abstract}
Resumo
O objetivo desse trabalho foi avaliar e comparar a composição centesimal, teor de ácido ascórbico, fibra alimentar e fósforo dos cogumelos mais cultivados no Brasil (Agaricus bisporus, Lentinula edodes e Pleorotus spp.). Cinco amostras de diferentes lotes e marcas, de cada espécie de cogumelo, foram analisadas segundo os métodos descritos pela "Association of Official Analytical Chemists International". Para sólidos totais, proteína, lipídeo, cinzas, carboidratos e fibra alimentar os valores médios obtidos, em base seca, foram, respectivamente: 9,37; 23,22; 4,71; 8,89;63,17; e 34,0 g. $100 \mathrm{~g}^{-1}$. Para fósforo e ácido ascórbico os valores médios encontrados em base úmida foram de 104,13 e $6,67 \mathrm{mg} .100 \mathrm{~g}^{-1}$, respectivamente. A avaliação da composição centesimal dos cogumelos estudados mostrou ser um alimento com características nutricionais excelentes, com alto teor de proteínas e fibras alimentares, além do baixo teor de lipídeos e fonte considerável de fósforo; apresentaram, entretanto, baixo teor de ácido ascórbico.

Palavras-chave: cogumelo; valor nutricional; fungos comestíveis; composição centesimal.
\end{abstract}

\begin{abstract}
The aim of this study was to evaluate and to compare the proximate composition, vitamin C (ascorbic acid), dietary fiber and phosphorus contents of the more cultivated mushrooms in Brazil (Agaricus bisporus, Lentinula edodes, and Pleorotus spp.). Five different batches, from different brands of each mushroom were analyzed according to methods described in the Association of Official Analytical Chemists International. For total solids, protein, fat, ash, carbohydrates and dietary fiber, the average values, on a dry weight basis, were respectively: 9.37, 23.22, 4.71, 8.89, 63.17 and $34.0 \mathrm{~g} .100 \mathrm{~g}^{-1}$. For phosphorus and vitamin C, the average values on a wet weight basis were: 104.13 and $6.67 \mathrm{mg} .100 \mathrm{~g}^{-1}$. From their compositions, the mushrooms studied here were shown to be excellent nutritional foods, presenting high protein and dietary fiber contents, low fat contents and reasonable sources of phosphorus, although poor vitamin $\mathrm{C}$ sources.

Keywords: mushroom; nutritional value; edible fungi; proximate composition.
\end{abstract}

\section{Introdução}

Os cogumelos são alimentos muito apreciados desde a idade antiga por se acreditar em seu elevado valor nutritivo e em seu potencial medicinal, além de ser classificado como uma especiaria nobre em pratos culinários. São conhecidas aproximadamente 2000 espécies comestíveis e cerca de 25 delas são cultivadas comercialmente ${ }^{10}$. Dentre essas, existem 3 espécies mais comumente cultivadas e consumidas no Brasil: A. bisporus, conhecido como champignon de Paris; L. edodes, como Shiitake; e Pleurotus, como shimeji ou hiratake ${ }^{20}$.

O consumo de cogumelos está aumentando na cultura ocidental, envolvendo um grande número de espécies além do popular "champignon"15. Um grande crescimento pode ser atestado pelos seguintes números: em 1995, a produção anual mundial foi de 2,0 milhões de toneladas e, em 2005, aumentou para 3,3 milhões de toneladas, ou seja, mais de $60 \%$ em $10 \operatorname{anos}^{12}$. A produção do Brasil não se encontra nessa estatística mundial e, segundo VILELA ${ }^{21}$, o País não possui estatísticas oficiais sobre a produção de cogumelos, mas sabe-se que a maior região produtora está localizada no Alto Tietê, em São Paulo. Nota-se que, no Brasil, está havendo um crescimento no consumo dos cogumelos e, conseqüentemente,

\footnotetext{
Recebido para publicação em 8/5/2006

Aceito para publicação em 24/01/2007 (001744)

Centro de Química de Alimentos e Nutrição Aplicada,

Instituto de Tecnologia de Alimentos - ITAL,

Av. Brasil, 2880, CEP 13073-001, Campinas - SP, Brasil,

e-mail: rfurlani@ital.sp.gov.br

2 Faculdade de Engenharia de Alimentos,

Universidade Estadual de Campinas - UNICAMP

*A quem a correspondência deve ser enviada
}

na produção e comercialização de tal produto. Esse fato se dá por haver, atualmente, maior divulgação de seu valor nutritivo e medicinal e por seu preço ter se tornado um pouco mais acessível à população.

Mas muito pouco se sabe a respeito da qualidade dos cogumelos comestíveis cultivados no Brasil, especialmente com respeito ao valor nutricional. Mesmo na literatura internacional, os dados encontrados são escassos e se referem a cogumelos cultivados em condições distintas das encontradas no Brasil. No Estado de São Paulo, principalmente na região de Mogi das Cruzes, o cultivo ainda é realizado de forma rudimentar, geralmente realizado por famílias chinesas que herdaram as técnicas por muitas gerações e sem conhecimentos científicos mais aprofundados ${ }^{10}$.

Informação a respeito da composição de alimentos tem se tornado cada vez mais importante para avaliar a sua qualidade. Para vitaminas, essas informações têm grande valor, uma vez que desempenham funções importantes no organismo humano e animal. Outros constituintes, como proteínas, lipídeos e fibras, também têm se tornado uma importante preocupação para profissionais das áreas da saúde e de alimentos. O consumidor também tem buscado fontes naturais de vitaminas além do interesse por produtos de boa qualidade.

Diante deste quadro, surge a necessidade de um levantamento que demonstre o real valor nutricional dos cogumelos comestíveis. Assim sendo, o presente trabalho teve por objetivo avaliar a composição centesimal, ácido ascórbico, fibra alimentar e fósforo em três espécies de cogumelos produzidos no Brasil (A. bisporus, L. edodes e P. ostreatus). 


\section{Material e métodos}

\subsection{Amostras}

As amostras de champignon de Paris, shiitake e shimeji foram compradas no comércio das cidades de Campinas e São Paulo, no período de março a abril de 2002. Para cada espécie de cogumelo foram adquiridos cinco lotes in natura de diferentes marcas. Cada lote foi dividido em 2 partes, uma destinada à análise da composição centesimal, teor de fósforo e de ácido ascórbico e outra, seca em estufa a $105^{\circ} \mathrm{C}$, destinada à análise do teor de fibra alimentar. Para determinação de fibra alimentar foram utilizados apenas três lotes.

\subsection{Métodos}

Para a determinação dos teores de sólidos totais, cinza, proteína e fibra alimentar, foram utilizados os métodos descritos pela $\mathrm{AOAC}^{1}$. O fator de conversão utilizado para proteína foi $4,38^{5}$. Para a determinação de lipídeos foi utilizado o método descrito por BLIGH e DYER 4 . O conteúdo de carboidratos nos cogumelos foi calculado por diferença. Todas as determinações foram realizadas em triplicata, com exceção da fibra alimentar que foi feita em quatro replicatas. O teor de fósforo foi determinado utilizando-se fosfomolibdovanadato, de acordo com o método espectrofotométrico descrito pela $\mathrm{AOAC}^{1}$. Para a determinação de ácido ascórbico, foi empregado o método titulométrico que se baseia na reação de oxi-redução do ácido ascórbico em meio ácido pela ação do 2,6-diclorofenolindofenol de sódio. As amostras foram extraídas com ácido oxálico ${ }^{3}$. A extração foi realizada em duplicata e a titulação em triplicata.

\subsection{Análise estatística}

Foi realizada análise de variância e teste de Tukey, utilizando-se o programa STATISTICA ${ }^{18}$. Foram avaliadas as diferenças significativas $(\mathrm{p}<0,05)$ para os teores de cada composto analisado para cada espécie.

\section{Resultados e discussão}

As Tabelas de 1 a 5 mostram os resultados obtidos nas determinações realizadas para a composição centesimal em três diferentes espécies de cogumelos. Os resultados estão apresentados em base seca, com exceção de sólidos totais que estão apresentados em base úmida.

Tabela 1. Teor de sólidos totais em cogumelos (\%)

\begin{tabular}{lccc}
\hline \multicolumn{1}{c}{ Lote } & Champignon & Shiitake & Shimeji \\
\hline 1 & $7,42 \pm 0,05^{\mathrm{d}}$ & $8,87 \pm 0,12^{\mathrm{c}}$ & $7,20 \pm 0,02^{\mathrm{e}}$ \\
2 & $7,87 \pm 0,17^{\mathrm{c}}$ & $9,78 \pm 0,15^{\mathrm{a}}$ & $11,97 \pm 0,03^{\mathrm{a}}$ \\
3 & $6,66 \pm 0,01^{\mathrm{e}}$ & $9,44 \pm 0,05^{\mathrm{b}}$ & $11,08 \pm 0,06^{\mathrm{b}}$ \\
4 & $9,77 \pm 0,05^{\mathrm{a}}$ & $5,41 \pm 0,01^{\mathrm{e}}$ & $8,96 \pm 0,05^{\mathrm{c}}$ \\
5 & $8,28 \pm 0,08^{\mathrm{b}}$ & $8,44 \pm 0,07^{\mathrm{d}}$ & $8,04 \pm 0,02^{\mathrm{d}}$ \\
Média & $8,00 \pm 1,07$ & $8,39 \pm 1,62$ & $9,23 \pm 1,71$ \\
\hline
\end{tabular}

"Médias de triplicata e estimativa de desvio padrão. Valores expressos em base úmida. Valores assinalados com a mesma letra na mesma coluna não diferem significativamente $(p<0,05)$, segundo teste de Tukey.
Os conteúdos de sólidos totais nos cogumelos, apresentados na Tabela 1 , ficaram na faixa de 8,00 a $9,23 \%$, confirmando o alto teor de umidade desses produtos ${ }^{5,6}$. Houve diferença significativa $(p<0,05)$ entre os lotes, possivelmente afetada por alguns fatores, tais como condições de cultivo, armazenamento pós-colheita, entre outros.

Observando-se os resultados apresentados na Tabela 2, nota-se que, na composição de todas as espécies analisadas, os carboidratos são os principais constituintes nutricionais apresentando um teor médio de $63,17 \%$, em base seca.

Nota-se que, para o champignon, houve diferença ( $p<0,05$ ) entre todos os lotes analisados. Para o shimeji, apenas dois lotes não diferiram significativamente entre si, tendo diferido das demais e, para o shiitake, apenas um lote diferiu significativamente $(\mathrm{p}<0,05)$ dos outros. Os valores médios para carboidratos encontrados para cada tipo de cogumelo estão próximos aos citados na literatura internacional ${ }^{7,9,14,22}$.

Tabela 2. Teor de carboidratos em cogumelos (\%) ${ }^{\mathrm{a}}$.

\begin{tabular}{llcc}
\hline \multicolumn{1}{c}{ Lote } & Champignon & Shiitake & Shimeji \\
\hline 1 & $50,42 \pm 0,55^{\mathrm{d}}$ & $70,68 \pm 2,60^{\mathrm{a}}$ & $75,74 \pm 0,29^{\mathrm{a}}$ \\
2 & $54,00 \pm 1,82^{\mathrm{c}}$ & $70,86 \pm 1,34^{\mathrm{a}}$ & $52,39 \pm 1,02^{\mathrm{d}}$ \\
3 & $65,05 \pm 0,52^{\mathrm{a}}$ & $70,69 \pm 0,71^{\mathrm{a}}$ & $65,40 \pm 0,31^{\mathrm{c}}$ \\
4 & $57,48 \pm 0,56^{\mathrm{b}}$ & $69,10 \pm 0,14^{\mathrm{ab}}$ & $67,64 \pm 1,03^{\mathrm{b}}$ \\
5 & $43,67 \pm 0,98^{\mathrm{e}}$ & $66,57 \pm 0,52^{\mathrm{b}}$ & $67,92 \pm 0,79^{\mathrm{b}}$ \\
Média & $54,12 \pm 7,42$ & $69,58 \pm 2,05$ & $65,82 \pm 7,86$ \\
\hline
\end{tabular}

"Valores calculados $(n=3)$. Valores expressos em base seca. Valores assinalados com a mesma letra na mesma coluna não diferem significativamente $(\mathrm{p}<0,05)$, segundo teste de Tukey.

Outro constituinte que se destaca na composição dos cogumelos é a proteína e os resultados obtidos estão apresentados na Tabela 3. Os diferentes lotes, para cada espécie apresentaram diferenças significativas para os teores de proteína. O valor médio para todas as espécies foi de aproximadamente $23 \%$.

O champignon apresentou os maiores valores para proteína e o teor médio de aproximadamente $28 \%$ em base seca, e está de acordo com o intervalo apresentado por CHANG e MILLES ${ }^{7}$ entre 23,9 e $34,8 \%$.

Para o shiitake, a quantidade de proteína média foi de 19\%, em base seca, ligeiramente superior aos dados apresentados por CHANG e MILES ${ }^{7}$ (13,4 a 17,5\%) e MANZI et al. ${ }^{13}$ (15,19\%).

Já para o shimeji, a média encontrada neste trabalho foi de $22 \%$, em base seca, valor que se enquadra nos intervalos apresentados por CHANG e MILES 7 , que foi de 10,5 a 30,4\%, e por MANZI et al. ${ }^{13}$, que foi de 19,93 a $34,73 \%$.

Tabela 3. Teor de proteína em cogumelos (\%)

\begin{tabular}{lccc}
\hline Lote & Champignon & Shiitake & Shimeji \\
\hline 1 & $31,57 \pm 0,33^{\mathrm{b}}$ & $17,97 \pm 1,53^{\mathrm{b}}$ & $16,19 \pm 0,38^{\mathrm{e}}$ \\
2 & $30,31 \pm 0,50^{\mathrm{c}}$ & $19,63 \pm 0,33^{\mathrm{ab}}$ & $33,73 \pm 0,70^{\mathrm{a}}$ \\
3 & $16,46 \pm 0,16^{\mathrm{e}}$ & $18,58 \pm 0,46^{\mathrm{ab}}$ & $22,91 \pm 0,27^{\mathrm{b}}$ \\
4 & $26,34 \pm 0,11^{\mathrm{d}}$ & $18,24 \pm 0,21^{\mathrm{b}}$ & $19,71 \pm 0,13^{\mathrm{c}}$ \\
5 & $37,59 \pm 0,32^{\mathrm{a}}$ & $20,48 \pm 0,24^{\mathrm{a}}$ & $18,59 \pm 0,29^{\mathrm{d}}$ \\
Média $^{\mathrm{d}}$ & $28,45 \pm 7,25$ & $18,98 \pm 1,16$ & $22,22 \pm 6,37$ \\
\hline
\end{tabular}

"Médias de triplicata e estimativa de desvio padrão. Valores expressos em base seca. Valores assinalados com a mesma letra na mesma coluna não diferem significativamente $(p<0,05)$, segundo teste de Tukey. 
Outro fator importante na constituição dos cogumelos foi o baixo teor de lipídeos, em que a média para as três espécies ficou ao redor de $5 \%$ e os resultados estão apresentados na Tabela 4. O champignon apresentou baixo teor de lipídeos, 5,4\% base seca, valor divergente daquele apresentado por CHEUNG ${ }^{8}$ que foi de $1,9 \%$, mas dentro do intervalo de 1,7 a $8,0 \%$ conforme apresentado por CHANG e MILLES 7 . O shiitake apresentou $4,4 \%$ de lipídeos em base seca, sendo que o valor apresentado por CHANG e MILES ${ }^{7}$ foi um pouco superior, 4,9 a 8,0\%. O teor de lipídeos do shimeji, como nos demais cogumelos, mostrouse baixo $(4,30 \%)$ e, também, acima do valor apresentado por CHANG e MILLES ${ }^{7}$. Os dados encontrados para os diferentes lotes de cada espécie foram diferentes $(\mathrm{p}<0,05)$ para as três espécies. Para o champignon, todos os lotes apresentaram diferença, já para o shiitake, apenas dois lotes não diferiram entre si ( $p>0,05)$. Para o shimeji, dos cinco lotes analisados, dois foram superiores, dois apresentaram resultados intermediários e um foi inferior.

Tabela 4. Teor de lipídeos em cogumelos (\%)ª

\begin{tabular}{lccc}
\hline Lote & Champignon & Shiitake & Shimeji \\
\hline 1 & $5,79 \pm 0,06^{\mathrm{b}}$ & $2,44 \pm 0,03^{\mathrm{d}}$ & $2,46 \pm 0,02^{\mathrm{c}}$ \\
2 & $4,83 \pm 0,18^{\mathrm{d}}$ & $4,06 \pm 0,05^{\mathrm{c}}$ & $5,12 \pm 0,06^{\mathrm{a}}$ \\
3 & $3,62 \pm 0,17^{\mathrm{e}}$ & $4,27 \pm 0,09^{\mathrm{c}}$ & $4,52 \pm 0,04^{\mathrm{b}}$ \\
4 & $5,24 \pm 0,09^{\mathrm{c}}$ & $4,91 \pm 0,08^{\mathrm{b}}$ & $4,35 \pm 0,11^{\mathrm{b}}$ \\
5 & $7,64 \pm 0,13^{\mathrm{a}}$ & $6,29 \pm 0,20^{\mathrm{a}}$ & $5,08 \pm 0,10^{\mathrm{a}}$ \\
Média & $5,42 \pm 1,37$ & $4,39 \pm 1,30$ & $4,30 \pm 1,01$ \\
\hline
\end{tabular}

"Médias de triplicata e estimativa de desvio padrão. Valores expressos em base seca. Valores assinalados com a mesma letra na mesma coluna não diferem significativamente $(\mathrm{p}<0,05)$, segundo teste de Tukey.

Os resultados do teor de cinzas estão apresentados na Tabela 5 e o valor médio encontrado foi de $9 \%$. O champignon mostrou-se com considerável quantidade de cinzas, média de aproximadamente $12 \%$ em base seca, superior aos demais. Esse valor é similar ao apresentado por $\mathrm{CHEUNG}^{9}$, que foi $10,3 \%$, ficando dentro do intervalo mencionado por CHANG e MILLES ${ }^{7}$, entre 7,7 e 12,0\%. Já o shiitake e o shimeji apresentaram valores coincidentes com os intervalos apresentados por CHANG e MILLES ${ }^{7}$. Também para cinzas, os valores entre os diferentes lotes de cada espécie foram diferentes.

Tabela 5. Teor de cinzas em cogumelos (\%)

\begin{tabular}{cccc}
\hline Lote & Champignon & Shiitake & Shimeji \\
\hline 1 & $12,23 \pm 0,05^{\mathrm{b}}$ & $8,92 \pm 0,16^{\mathrm{a}}$ & $5,61 \pm 0,05^{\mathrm{d}}$ \\
2 & $10,86 \pm 0,04^{\mathrm{c}}$ & $5,44 \pm 0,03^{\mathrm{d}}$ & $8,77 \pm 0,08^{\mathrm{a}}$ \\
3 & $14,79 \pm 0,39^{\mathrm{a}}$ & $6,46 \pm 0,14^{\mathrm{c}}$ & $7,17 \pm 0,05^{\mathrm{c}}$ \\
4 & $10,94 \pm 0,04^{\mathrm{c}}$ & $7,75 \pm 0,17^{\mathrm{b}}$ & $8,30 \pm 0,23^{\mathrm{b}}$ \\
5 & $11,10 \pm 0,09^{\mathrm{c}}$ & $6,65 \pm 0,16^{\mathrm{c}}$ & $8,42 \pm 0,21^{\mathrm{ab}}$ \\
Média & $11,98 \pm 1,54$ & $7,04 \pm 1,24$ & $7,65 \pm 1,20$ \\
\hline
\end{tabular}

"Médias de triplicata e estimativa de desvio padrão. Valores expressos em base seca. Valores assinalados com a mesma letra na mesma coluna não diferem significativamente $(\mathrm{p}<0,05)$, segundo Teste de Tukey.

Na Tabela 6, estão apresentados os resultados, em base seca, obtidos para fibra alimentar. Pode-se notar que o teor de fibra alimentar para os cogumelos é alto, apresentando um teor médio de $34 \%$ para as três espécies. Para o champig- non, as fibras alimentares foram de $20,4 \%$, valor superior ao encontrado por CHANG e MILLES ${ }^{7}$ entre 8,0 e 10,4\%, porém similar aos dados de CHEUNG $^{9}$ com teor de 18,2\%. Essa espécie foi a que apresentou o menor valor para fibra alimentar dentre as analisadas. Quanto ao shiitake, o valor encontrado foi de $41,9 \%$ em base seca, valor próximo à média mostrada por $\mathrm{CHEUNG}^{8}$, porém muito superior ao citado por CHANG e MILLES ${ }^{7}$, entre 7,3 e 8,9\%, para o mesmo cogumelo. O shimeji, assim como o shiitake, também se destacou pela quantidade de fibras alimentares, 39,6\% em base seca, valor ligeiramente superior ao mostrado por $\mathrm{CHEUNG}^{8}$, porém muito maior em relação ao apresentado por CHANG e MILES ${ }^{7}$.

Tabela 6. Teor de fibra alimentar em cogumelos (\%) ${ }^{a}$.

\begin{tabular}{llcc}
\hline \multicolumn{1}{c}{ Lote } & Champignon & Shiitake & Shimeji \\
\hline 1 & $17,67 \pm 0,50^{\mathrm{c}}$ & $47,60 \pm 1,78^{\mathrm{a}}$ & $51,25 \pm 2,17^{\mathrm{a}}$ \\
2 & $22,87 \pm 0,21^{\mathrm{a}}$ & $37,26 \pm 0,12^{\mathrm{c}}$ & $22,30 \pm 1,59^{\mathrm{c}}$ \\
3 & $20,78 \pm 1,27^{\mathrm{b}}$ & $40,91 \pm 0,47^{\mathrm{b}}$ & $45,31 \pm 0,64^{\mathrm{b}}$ \\
Média & $20,44 \pm 2,34$ & $41,92 \pm 4,57$ & $39,62 \pm 13,12$ \\
\hline
\end{tabular}

Médias de quatro replicatas e estimativa de desvio padrão. Valores expressos em base seca. Valores assinalados com a mesma letra na mesma coluna não diferem significativamente ( $\mathrm{p}<0,05)$, segundo teste de Tukey.

Os resultados para as análises de ácido ascórbico podem ser observados na Tabela 7 e estão apresentados em base úmida. Houve diferença significativa $(\mathrm{p}<0,05)$ para os diferentes lotes de cada espécie. Os valores encontrados neste trabalho superam os descritos por MATTILA et al. ${ }^{15}$, que encontraram 1,3; 2,1 e 1,6 mg. $100 \mathrm{~g}^{-1}$ para o champignon, shiitake e shimeji, respectivamente.

Tabela 7. Teor de ácido ascórbico em cogumelos (mg.100 $\left.\mathrm{g}^{-1}\right)^{\mathrm{a}}$.

\begin{tabular}{llcc}
\hline Lote & Champignon & Shiitake & Shimeji \\
\hline 1 & $4,09 \pm 0,17^{\mathrm{d}}$ & $7,54 \pm 0,29^{\mathrm{b}}$ & $6,53 \pm 0,30^{\mathrm{bc}}$ \\
2 & $7,79 \pm 0,66^{\mathrm{a}}$ & $7,39 \pm 0,08^{\mathrm{b}}$ & $7,46 \pm 0,28^{\mathrm{a}}$ \\
3 & $7,09 \pm 0,19^{\mathrm{b}}$ & $9,74 \pm 0,19^{\mathrm{a}}$ & $5,35 \pm 0,12^{\mathrm{d}}$ \\
4 & $5,77 \pm 0,14^{\mathrm{c}}$ & $5,80 \pm 0,05^{\mathrm{c}}$ & $6,36 \pm 0,05^{\mathrm{c}}$ \\
5 & $6,77 \pm 0,15^{\mathrm{b}}$ & $5,50 \pm 0,04^{\mathrm{d}}$ & $6,79 \pm 0,04^{\mathrm{b}}$ \\
Média & $6,30 \pm 1,34$ & $7,19 \pm 1,55$ & $6,50 \pm 0,72$ \\
\hline
\end{tabular}

${ }^{a}$ Médias de seis replicatas e estimativa de desvio padrão. Valores expressos em base úmida. Valores assinalados com a mesma letra na mesma coluna não diferem significativamente $(\mathrm{p}<0,05)$, segundo Teste de Tukey.

Os cogumelos analisados apresentaram um alto teor de fósforo e os resultados estão apresentados na Tabela 8, sendo que a média para as espécies foi de $104 \mathrm{mg} .100 \mathrm{~g}^{-1}$, em base úmida. O champignon e o shiitake apresentaram os valores médios de 113,3 e 89,4 mg. $100 \mathrm{~g}^{-1}$, respectivamente, que foram ligeiramente superiores aos encontrados por MATTILA et al. ${ }^{15}$, que foram entre 98 e $73 \mathrm{mg} .100 \mathrm{~g}^{-1}$, respectivamente. Para o shimeji, o valor encontrado foi de 109,7 mg.100 $\mathrm{g}^{-1}$ e está muito próximo ao apresentado por MATTILA et al. ${ }^{15}$, que foi de $111 \mathrm{mg} .100 \mathrm{~g}^{-1}$. Novamente houve diferenças significativas ( $p<0,05)$ para os diferentes lotes de cada espécie. 
Tabela 8. Teor de fósforo em cogumelos $\left(\mathrm{mg} \cdot 100 \mathrm{~g}^{-1}\right)^{a}$.

\begin{tabular}{lccr}
\hline Lote & Champignon & Shiitake & \multicolumn{1}{c}{ Shimeji } \\
\hline 1 & $118,0 \pm 0,7^{\mathrm{b}}$ & $103,6 \pm 4,4^{\mathrm{a}}$ & $45,4 \pm 3,4^{\mathrm{d}}$ \\
2 & $117,4 \pm 2,3^{\mathrm{b}}$ & $111,1 \pm 1,4^{\mathrm{a}}$ & $204,9 \pm 6,7^{\mathrm{a}}$ \\
3 & $74,5 \pm 4,3^{\mathrm{c}}$ & $105,0 \pm 3,2^{\mathrm{a}}$ & $111,1 \pm 8,9^{\mathrm{b}}$ \\
4 & $132,0 \pm 0,09^{\mathrm{a}}$ & $60,4 \pm 2,7^{\mathrm{b}}$ & $103,6 \pm 3,2^{\mathrm{b}}$ \\
5 & $124,4 \pm 2,9^{\mathrm{b}}$ & $67,1 \pm 3,2^{\mathrm{b}}$ & $83,4 \pm 3,0^{\mathrm{c}}$ \\
Média & $113,3 \pm 22,5$ & $89,4 \pm 23,7$ & $109,7 \pm 59,0$ \\
\hline
\end{tabular}

"Médias de triplicata e estimativa de desvio padrão. Valores expressos em base úmida. Valores assinalados com a mesma letra na mesma coluna não diferem significativamente $(\mathrm{p}<0,05)$, segundo teste de Tukey.

Pelo teste de Tukey, pode-se notar que ocorreu, para todos os nutrientes analisados, diferença significativa $(\mathrm{p}<0,05)$ entre médias das análises dos diferentes lotes da mesma espécie. Essas diferenças podem ter sido causadas por diversos fatores, já que um cogumelo pode ter composição diversa quando cultivado em regiões ou países diferentes ${ }^{2,11,16,17}$. Além desses fatores apresentados, STURION e OETTERER ${ }^{19}$ afirmam que o tipo de substrato utilizado no cultivo influencia a composição química dos cogumelos, principalmente quanto ao teor de proteínas, fibras e minerais. E como as amostras analisadas eram provenientes de marcas diferentes, as condições edafoclimáticas, bem como o estádio de desenvolvimento do basidiocarpo, condições de cultivo, manuseio e colheita podem ter contribuído para essa diferença.

\section{Conclusões}

Os cogumelos champignon, shiitake e shimeji, por sua composição química, constituem um alimento com excelente valor nutritivo, pois apresentam alto teor de proteínas e fibras alimentares, além de conterem baixo teor de lipídeos. Há uma considerável quantidade de fósforo e os valores encontrados para ácido ascórbico não são expressivos para considerá-los fonte dessa vitamina.

\section{Agradecimentos}

Os autores agradecem à Fundação de Amparo à Pesquisa do Estado de São Paulo (Fapesp) pelo auxílio financeiro.

\section{Referências bibliográficas}

1. ASSOCIATION OF OFFICIAL ANALYTICAL CHEMISTS INTERNATIONAL AOAC. Official Methods of Analysis. $16^{\circ}$ ed., $3^{\circ}$ rev., Gaitherburg, Patricia Cunniff, 1997. v. 2, 1141 p.

2. BANIK, S.; NANDI, R. Effect of supplementation of rice straw with biogas residual slurry manure on the yield, protein and mineral contents of oyster mushroom. Industrial Crops and Products, v. 20, n. 3, p. 311-319, nov. 2004.

3. BENASSI, M. T.; ANTUNES, A. J. A Comparison of metaphosphoric and oxalic acids as extractant solutions for the determination of vitamin $\mathrm{C}$ in selected vegetables. Arquivos de Biologia e Tecnologia, Curitiba, v. 31, n. 4, p. 507-513, out./dez. 1988.

4. BLIGH, E. C.; DYER, W. J. A Rapid method of total lipid extraction and purification. Canadian Journal Biochemistry Physiology, Ottawa, v. 37, n. 8, p. 911-917, ago. 1959.

5. BREENE, W. M. Nutritional and medicinal value of specialty mushrooms. Journal of Food Protection, Des Moines, v. 53, n. 10, p. 883-894, out. 1990.
6. CHANG, R. Functional properties of edible mushrooms. Nutrition Reviews, v. 54, n. 11, p. S91-S93, nov. 1996.

7. CHANG, S. T.; MILlES, P. G. Edible Mushrooms and their cultivation. Boca Raton: CRC Press, 1989. 345p.

8. CHEUNG, P. C. K. Dietary fiber content and composition of some cultivated edible mushroom fruiting bodies and mycelia. Journal of Agricultural and Food Chemistry, Easton, v. 44, n. 2, p. 468-471. fev. 1996.

9. CHEUNG, P. C. K. Dietary fiber content and composition of some edible fungi determined by two methods of analysis. Journal of Agricultural and Food Chemistry, Easton, v. 73, n. 2, p. 255-260. fev. 1997.

10. COUTINHO, L. N. Cultivo de Espécies de Cogumelo Comestíveis. Disponível em: <http://www.geocities.com/esabio.geo/cogumelo/ agaricus.htm>. Acesso em: 13 maio 2004.

11. EKANEM, E. O.; UBENGAMA, V. S. Chemical composition, antinutritional factors and shelf-life of oyster mushroom (Pleurotus ostreatus). Journal of Food Science Technology, Mysore, v. 39, n. 6, p. 635-338, 2002.

12. FAOSTAT Food and Agriculture Organization of the United Nations. Disponível em: <http://faostat.fao.org/site/567/DesktopDefault. aspx?PageID=567> Acesso em: 24 janeiro 2007.

13. MANZI, P.; GAMBELli, L.; MARCONI, S.; VIVANTI, V.; PIZZOFERRATO, L. Nutrients in edible mushrooms: an interspecies comparative study. Food Chemistry, Oxford, v. 65, n. 4, p. 477-482, jun. 1999.

14. MANZI, P.; PIZZOFERRATO, L.; AGUZZI, A. Nutritional value of mushrooms widely consumed in Italy. Food Chemistry, Oxford, v. 73, n. 3, p. 321-325, mai. 2001.

15. MATTILA, P.; KONKO, K.; EUROLA, M.; PIHLAVA, J. M.; ASTOLA, J.; VAHTERISTO, L.; HIETANIEMI, V.; KUMPULAINEN, J.; VALTONEN, M.; PIIRONEN V. Contents of vitamins, mineral elements, and phenolic compounds in cultivated mushrooms. Journal of Agricultural and Food Chemistry, Washington, v. 49, n. 5, p. 2343-2348. mai. 2001.

16. RANZANI, M. R. T. C.; STURION, G. L. Avaliação da composição em aminoácidos de Pleurotus spp. cultivados em folha de bananeira. Archivos Latinoamericanos de Nutricion, Caracas, v. 48, n. 4, p. 339-348, mar. 1998.

17. RIOS-HURTADO, A.; TORRES-TORRES, G.; MEDINA-RIVAS, M. A. Caracterización bromatológica de la seta (Pleurotus sajor-caju) producida en cuatro sustratos orgánicos. Alimentaria, Madrid, v. 40, n. 349, p. 85-89, dez. 2003.

18. STATSOFT, INC. (2000). Statistica for Windows [Computer program manual]. Tulsa, OK: StatSoft, Inc.

19. Sturion, G. L.; OetTerer, M. Composição química de cogumelos comestíveis (Pleurotus spp.) originados de cultivos em diferentes substratos. Ciência e Tecnologia de Alimentos, Campinas, v. 15, n. 2, p. 189-193, jul./dez. 1995.

20. URBEN, A. F.; OLIVIERA, H. C. B.; VIEIRA, W.; CORREIA, M. J.; URIARTT, A. H. Produção de cogumelos por meio de tecnologia chinesa modificada. Brasília : Embrapa, 2001. 151 p.

21. VILELA, P. S. Cogumelos - mercado e comercialização. Disponível em: $<$ www.faemg.org.br/content.aspx?code $=353 \&$ parentpath $=$ n one; $13>$. Acesso em: 24 janeiro 2007.

22. YANG, J. L.; LIN H. C.; MAU J. L. Non-volatile taste components of several commercial mushrooms. Food Chemistry, Oxford, v. 72 , n. 4 , p. $465-471$, mar. 2001. 